\title{
Processos de significação na elaboração de conhecimentos de alunos com necessidades educacionais especiais'
}

\author{
Maria Inês Bacellar Monteiro"
}

Ana Paula de Freitas ${ }^{\text {III }}$

\section{Resumo}

Este estudo aborda a temática da educação inclusiva, com interesse nas práticas educacionais orientadas por relações de ensino significativas. Temos como objetivo refletir sobre o papel de educadores e pares diante das possibilidades de desenvolvimento e aprendizagem de alunos com necessidades educacionais especiais. Partimos do pressuposto de que o sujeito interativo elabora conhecimentos sobre objetos em processos necessariamente mediados pelo outro e constituídos pela linguagem, pelo funcionamento dialógico. Assumimos os princípios metodológicos da pesquisa histórico-cultural e utilizamos como forma de análise o que se denomina análise microgenética. Utilizamos um banco de dados composto por filmagens de práticas pedagógicas de uma sala de aula e gravações de reuniões periódicas ocorridas entre uma das pesquisadoras e a professora de um aluno do $1^{\circ}$ ano do ensino fundamental, com 8 anos de idade e atraso no desenvolvimento global. Os resultados mostram que houve participação do outro nas atividades propostas, configurando relações intersubjetivas nem sempre harmoniosas e diferentes formas de envolvimento entre a professora e o aluno na dinâmica dialógica. As ações da professora ganham um lugar importante ao reconhecermos a relevância de sua participação no processo de elaboração do conhecimento escolar. Destacamos o papel que o outro representa no processo de ensino e aprendizagem e explicitamos modos de ação que podem contribuir, no âmbito educacional, para tornar o processo de ensino significativo também para os alunos com necessidades educacionais especiais.

\section{Palavras-chave}

Teoria histórico-cultural - Educação inclusiva - Processos de significação - Conhecimento escolar.

I- Agradecemos à Fapesp e ao PROESP (Capes) os auxilios recebidos.

II- Universidade Metodista de Piracicaba, Piracicaba, SP, Brasil.

Contato: mbmontei@unimep.br

III-Centro Universitário Moura Lacerda, Campinas, SP, Brasil.

Contato: ana.freitas@mouralacerda.edu.br 


\title{
Signification processes in the elaboration of knowledge by pupils with special education needs'
}

Maria Inês Bacellar Monteiro"

Ana Paula de Freitas ${ }^{\text {II }}$

\begin{abstract}
This study deals with the theme of inclusive education, and focuses on the educational practices oriented by significant teaching relations. We have as an objective to reflect upon the role of educators and peers in the face of the possibilities of development and learning of pupils with special education needs. We assume that the interactive subject elaborates knowledge about objects in processes that are necessarily mediated by the other and constituted by the language, by the dialogical functioning. We adopt the methodological principles of historic-cultural research, and we use as a form of analysis what is denominated micro-genetic analysis. We make use of a database composed of video recordings of pedagogical practices in a classroom and recordings of periodical meetings between one of the researchers and the teacher of an eight-year-old pupil of the first year of primary education who had global development delay. The results show that there was participation of the other in the activities proposed, configuring intersubjective relations which were not always harmonious, and different forms of connection between the teacher and pupil in the dialogical dynamics. The actions of the teacher acquired an important aspect when we recognize the relevance of her participation in the process of elaboration of school knowledge. We emphasize the role that the other takes in the teaching and learning process, and we clarify modes of action that can contribute, within the educational sphere, to make the teaching process significant also to pupils with special education needs.
\end{abstract}

\section{Keywords}

Historic-cultural theory - Inclusive education - Processes of signification - School knowledge.

I- The authors wish to acknowledge the support of Fapesp and PROESP (Capes). II- Universidade Metodista de Piracicaba, Piracicaba, $S P$, Brazil.

Contact:mbmontei@unimep.br

III-Centro Universitário Moura Lacerda, Campinas, SP, Brazil.

Contact: ana.freitas@mouralacerda.edu.br 
A temática da educação inclusiva tem sido amplamente discutida por educadores e pesquisadores, sobretudo a partir de 1996, com a priorização dada ao ensino de alunos com necessidades educacionais especiais na rede regular de ensino (BRASIL, 1996). Entre debates, embates e avanços, é fato que, na educação inclusiva que está em curso, ainda existem muitos desafios a serem vencidos. Como afırma Beyer (2003), há um sentimento de incompletude das redes de ensino - particularmente das escolas e dos professores - ao tentarem fazer cumprir a legislação educacional vigente.

Em nossos trabalhos e pesquisas sobre a temática, temos constatado esse sentimento de incompletude a partir de profundas inquietações sobre o fazer cotidiano relatadas a nós pelas professoras com quem trabalhamos. Tomamos como exemplo a fala de uma professora regente de uma classe do $1^{\circ}$ ano de ensino fundamental que possui, entre seus alunos, um com necessidades educacionais especiais. Durante um dos encontros realizados com ela, no qual tínhamos o objetivo de refletir sobre as condições de ensino na sala de aula e pensar em indícios das possibilidades de desenvolvimento do referido aluno, a professora nos disse:

A gente já está em agosto, a maioria dos alunos já está alfabética, já tem alguns lendo... Aí eu me preocupo, assim, [com] o que eu posso fazer mais pra ele, porque ele tá... Eu percebo que ele tem vontade de aprender, mas eu não sei o que posso fazer... Eu tenho receio que [...] a família... 0 que o pai e a mãe [...] querem [...]? Que ensine a ler e a escrever, aí a gente falou, né? Pra ficar mais um ano comigo, eu percebo que isso é importante pra ele, porque ele se sente tranquilo, se sente seguro, mas, assim, eu falo, será que eu vou conseguir fazer isso?

A fala da professora, a nosso ver, revela que ela se sente despreparada para lidar com esse aluno, sobretudo em relação aos caminhos alternativos e recursos especiais ${ }^{1}$ adequados para auxiliá-lo na aprendizagem da leitura e da escrita. Seus dizeres trazem indícios de que ela percebe seu aluno como alguém com vontade para aprender; revelam ainda que ela tem consciência de que a família espera da escola e particularmente da professora - a realização de um trabalho efetivo que permita ao aluno o acesso ao conhecimento escolar.

A partir das inquietações explicitadas por essa docente, temos o objetivo de refletir sobre o papel dos educadores e seus pares diante das possibilidades de desenvolvimento e aprendizagem de alunos com necessidades educacionais especiais que estão inseridos na rede regular de ensino. Pretendemos contribuir para uma discussão sobre práticas educativas que sejam orientadas por relações de ensino significativas. Nos dizeres de Smolka (2010, p. 128), ao comparar o ato de ensinar à análise realizada por Vigotski sobre a transformação do movimento de pegar do bebê em gesto de apontar:

[...] ensinar seria, assim, um trabalho com signos, um trabalho de significação por excelência, que implica incansáveis gestos indicativos nas orientações dos olhares, nas configurações dos objetos, nas formas de referir, de conceituar.

Orientamo-nos pela perspectiva histórico-cultural do desenvolvimento humano, sobretudo pela tese de Vigotski sobre a gênese social das funções mentais superiores, ou seja, aquelas tipicamente humanas, bem como pelas ideias do autor sobre a relação entre desenvolvimento e aprendizagem.

Em seu manuscrito sobre a psicologia concreta do homem, Vigotski (2000) esclarece sua lei geral do desenvolvimento humano ao apontar sua natureza histórica e social. Ele apresenta sua posição diante do

1- Ao utilizarmos as expressões caminhos alternativose recursos especiais, remetemo-nos aos estudos de Vigotski (1997) sobre a deficiência e os indivíduos com deficiência. Tais noções serão problematizadas no decorrer deste texto. 
desenvolvimento argumentando que "qualquer função psicológica superior foi externa significa que ela foi social antes de se tornar função, ela foi uma relação social entre duas pessoas" (VIGOTSKI, 2000, p. 24). Para o autor, o desenvolvimento cultural da criança pode ser compreendido em dois planos: primeiro, em um plano social, entre as pessoas; em seguida, "dentro da criança” (p. 26). Nessa afırmação está implícito o conceito de internalização.

Pino (2000) busca problematizar o sentido do social e do cultural na obra de Vigotski e salienta que a mediação do outro é condição para o desenvolvimento. Ele afırma que, "segundo Vigotski, o desenvolvimento cultural passa por três estágios ou momentos [...]: o desenvolvimento em si, para os outros e para si" (PINO, 2000, p. 65). 0 primeiro momento constitui-se pela realidade natural ou biológica da criança. Num segundo momento, essa realidade natural - ou seja, o que está dado - adquire significação para os outros. E o terceiro momento é aquele em que a significação que os outros atribuem ao dado natural tornase significativa para si, isto é, para o indivíduo singular. 0 exemplo mais característico desse processo nos textos de Vigotski (1987, 1991a, 2000) refere-se ao gesto de apontar.

Segundo Smolka (2000), o processo de formação do funcionamento mental dá-se à medida que os sujeitos são afetados por signos e sentidos produzidos nas relações com os outros. As ações humanas adquirem múltiplos significados e sentidos, tornando-se práticas significativas, a depender das posições e dos modos de participação dos sujeitos nas interações.

A autora procura problematizar a dinâmica da significação como produção humana de signos e sentidos e discute as consequências dessa dinâmica para as relações de ensino. Para ela, os esforços de Vigotski (1987, 2000) ao propor a emergência da dimensão semiótica - isto é, a produção de signos, o princípio da significação - como chave para se compreender a conversão das relações sociais em função mental trazem implicações radicais para o que se denomina relações de ensino. Nesse sentido, Smolka (2000) compreende o ato de ensinar como um trabalho com signos, um trabalho de significação por excelência, que implica incansáveis gestos indicativos nas orientações dos olhares, nas configurações dos objetos, nas formas de referir e de conceituar.

A teoria histórico-cultural traz contribuições importantes sobre a relação entre desenvolvimento e aprendizagem. Vigotski (1987, 1991a) esclarece que o desenvolvimento é suscitado e impulsionado pela aprendizagem, sendo que esta depende de condições de desenvolvimento. Para uma melhor compreensão de tal relação, o autor propõe o conceito de zona de desenvolvimento proximal, cuja principal ideia refere-se à relação existente entre desenvolvimento e aprendizagem e à ação colaborativa de outra pessoa. Segundo ele, a aprendizagem, ao ser realizada em uma ação colaborativa, seja do adulto ou entre pares, cria possibilidades de desenvolvimento. No que concerne ao conceito de zona de desenvolvimento proximal, Freitas (2001, p. 27-28) afirma:

O desenvolvimento proximal, visto como
desenvolvimento emergente, supõe a
participação do outro no processo de
aprendizado dos indivíduos, corresponde
ao espaço onde ocorrem os processos
de elaboração compartilhada. Sendo
assim, fica reiterada a tese de que o
desenvolvimento psicológico depende das
condições sociais em que é produzido.

No âmbito educacional, o referido conceito tem sido amplamente utilizado e alguns autores buscam elaborar diretrizes para as práticas educativas (MORTIMER; CARVALHO, 1996 apud FREITAS, 2001; COLAÇO et al., 2007; FERREIRA, 2008). Ancorada nas teses centrais de Vigotski, Góes (1997) apresenta contribuições fundamentais sobre a participação do outro e o papel da linguagem na elaboração do conhecimento. Ela se apoia na concepção de um sujeito interativo 
que elabora conhecimentos sobre objetos, em processos necessariamente mediados pelo outro e constituídos pela linguagem, pelo funcionamento dialógico. A autora salienta que, no âmbito educacional, as relações intersubjetivas são muitas vezes consideradas de maneira prescritiva e o outro é visto como aquele que sempre ajuda, partilha, guia, cria suportes, estabelece pontes. Porém, o desenvolvimento parece acontecer tanto em acordo quanto em desacordo com as características uniformes, esperadas ou idealizadas das relações entre sujeitos, isto é, ainda que as relações intersubjetivas não sejam harmoniosas. 0 outro tem um papel contraditório e o jogo dialógico que constitui a relação entre sujeitos não tende a apenas uma direção; abrange circunscrição, expansão, dispersão e estabilização de significados e envolve o deslocamento forçado de certas operações de conhecimento.

Consideramos que ainda é preciso refletir mais profundamente sobre o que se espera dos educadores e alunos em relação a essa ação colaborativa. 0 que vem a ser agir colaborativamente? A ideia de ação colaborativa atrelada ao conceito de significação remete-nos à procura da compreensão sobre as relações que se estabelecem em sala de aula, que permitem a elaboração de novos sentidos pelo grupo de alunos e pelo professor.

Baseamo-nos na visão de que a elaboração de conhecimentos dá-se na interação entre sujeitos, em processos mediados pelo outro e pela linguagem. Partimos da ideia de que o conceito de zona de desenvolvimento proximal mostra-se relevante para a discussão, desde que seja considerado parte inseparável do desenvolvimento como processo dialético, fundamentado nas dimensões cultural e semiótica do funcionamento humano.

\section{Caminhos metodológicos}

Neste estudo, assumimos os princípios metodológicos da pesquisa histórico-cultural, tal como proposto por Vigotski (1991a, 1991b). 0 autor baseia-se na abordagem materialista dialética da análise da história humana e aponta uma nova descrição metodológica, focalizando:

(1) uma análise do processo em oposição a uma análise do objeto; (2) uma análise que revela as relações dinâmicas ou causais, reais, em oposição à enumeração das características externas de um processo, isto é, uma análise explicativa e não descritiva; e (3) uma análise do desenvolvimento que reconstrói todos os pontos e faz retornar à origem o desenvolvimento de uma determinada estrutura. (VIGOTSKI, 1991a, p. 74)

Como forma de análise, utilizamos o que se denomina análise microgenética. Góes (2000) a define como uma forma de construção de dados que requer a atenção aos detalhes e o recorte de episódios interativos, sendo o exame orientado para o funcionamento dos sujeitos focais, as relações intersubjetivas e as condições sociais da situação, o que resulta num relato minucioso dos acontecimentos.

Apoiados na perspectiva e nas formas de análise expressas aqui, analisamos dois episódios extraídos do banco de dados das pesquisadoras referente a um estudo maior realizado em uma escola municipal de ensino fundamental de uma cidade do interior do Estado de São Paulo. 0 referido banco de dados é composto por filmagens de situações de uma sala de aula de $1^{\circ}$ ano do ensino fundamental com 23 alunos e gravações de reuniões periódicas entre uma das pesquisadoras e Lourdes, ${ }^{2}$ a professora do aluno focalizado no estudo. As filmagens foram feitas entre novembro de 2009 a novembro de 2010, considerando-se o período letivo; as reuniões com a professora ocorreram durante o ano de 2010. Realizamos a tarefa de transcrição minuciosa dos dados das filmagens e gravações, procurando revelar indícios das relações intersubjetivas e das condições de produção dos acontecimentos em curso.

2- Todos os nomes utilizados são fictícios para preservar a identidade dos sujeitos. 
0 aluno é Gil, 8 anos, que na época da pesquisa de campo frequentava o $1^{\circ}$ ano do ensino fundamental. Gil nasceu prematuro, pesando $1,1 \mathrm{~kg}$ e medindo $30 \mathrm{~cm}$. Segundo relato de sua mãe, ele não apresentou dificuldades motoras: aos 7 meses, já ficava sentado e engatinhava; com 1 ano e 3 meses já andava. Em relação ao desenvolvimento da linguagem oral, a mãe relatou que Gil demorou para falar e as primeiras palavras surgiram quando ele tinha 4 anos. Até então, usava gestos indicativos e balbucios. Segundo o diagnóstico neurológico, Gil apresenta uma má formação do desenvolvimento cortical com agnosia verbal auditiva e apraxia fonoarticulatória. ${ }^{3}$

Em relação à sua história escolar, em 2008, aos 6 anos de idade, Gil ingressou no $1^{\circ}$ ano do ensino fundamental. Em 2009 e 2010, permaneceu no $1^{\circ}$ ano e com a mesma professora. Em 2011, passou para o $2^{\circ}$ ano.

Lourdes, a professora, possui formação em Magistério e cursa Pedagogia em uma universidade privada. É professora da rede escolar municipal desde 2001.

\section{Resultados e discussões}

Com o intuito de refletir sobre as relações que se estabelecem no espaço escolar e que permitem a elaboração de novos sentidos pelo grupo de alunos e pela professora, apresentamos aqui dois episódios. 0 primeiro refere-se a uma situação ocorrida em sala de aula e o segundo, a um dos encontros realizados entre uma das pesquisadoras e a professora. Optamos pela transcrição em ortografia regular das falas dos envolvidos. Os gestos e as ações dos participantes estão descritos entre colchetes.

\section{Episódio 1}

Situação: As carteiras estão dispostas em semicírculo. Todos copiam o cabeçalho

3 - A agnosia verbal auditiva refere-se a uma falha no reconhecimento de estímulos linguísticos sem que a audição esteja prejudicada. A apraxia fonoarticulatória é uma desordem na programação motora da fala (MURDOCH, 1997). e a rotina do dia escritos na lousa pela professora. No cabeçalho constam as seguintes informações: nome da cidade; data, com dia, mês e ano; nome da escola; nome da professora e nome do ajudante do dia. $\mathrm{Na}$ rotina constam as atividades que serão realizadas ao longo do dia. Gil está sentado entre dois alunos, uma menina e um menino - Jane e Caio -; como os demais colegas, também copia o cabeçalho. A professora está em pé e caminha pela sala, olhando para os cadernos de cada aluno. 0 caderno de Gil está aberto e ele está escrevendo na página da esquerda, mas, como escreve em letras de forma muito grandes, às vezes ultrapassa para a folha da direita. Isso já ocorreu em outros momentos e a professora já chamou sua atenção para o fato. Quando ela se aproxima, ele começa a apagar a página da direita.

1. Professora: Aqui, ó, aqui tá certinho, aqui... não precisa apagar, faz a letra "i". 0 que você escreveu aqui? [Vai apontando com o dedo indicador para cada linha que Gil havia copiado.]

2. Gil: [Não responde.]

3. Professora: Olha lá! [Aponta a lousa.] Esse tá certo. [Indica algo no caderno.]

4. Caio: Aqui. [Indica algo no caderno de Gil.] 5. Professora: É, ele já vai corrigir. [Dirige-se ao aluno Caio e continua a caminhar pela sala.]

6. Gil: [Continua a apagar.]

[...]

7. Professora: Só pra quem terminou, viu, Jane. Eu vou passar de novo olhando os cadernos. [Pede para Jane distribuir a atividade do dia para os alunos que já haviam terminado a cópia.]

8. Jane: [Distribui a atividade.]

9. Professora: E você, Gil, cadê o seu? Você já terminou?

10. Gil: [Olha para o caderno e vira a página, voltando para a página correspondente à cópia do dia.]

11. Professora: Terminou? 
12. Gil: [Aceno positivo com a cabeça.]

13. Professora: Aqui tá certo, ó. [Apontando algo no caderno dele.]

14. Gil: [Olha para o que a professora está apontando.]

15. Professora: 0 que você fez aqui?

16. Gil: [Pega a borracha e começa a apagar.]

17. Professora: Re-crei-o [fala de modo silabado]. Faltou uma letra "r" no meio. [Aponta no caderno.]

18. Gil: [Olha para a professora e para o caderno.]

19. Professora: Faz o "r". [Pega a borracha e apaga algo.]

20. Gil: [Escreve.]

21. Professora: Foi o 3, o 4! [Indicando no caderno de Gil os itens da rotina que ele já havia copiado.] Vê se você consegue escrever. [Apaga o que Gil havia escrito à frente do número quatro e indica o lugar na folha onde deve ser escrito. Observa o caderno e vê que há várias palavras escritas na página da direita; apaga tudo o que está fora da ordem.] Agora é no outro lado, o 4 está aqui, mas tá inteiro aqui, olha lá pra lousa.

22. Gil: [Permanece com o caderno aberto sobre a carteira, observa o movimento da sala por uns instantes e volta a escrever.]

23. Pesquisadora: Acabou? Deixa eu ver.

24. Gil: [Não responde e volta a folhear o caderno. Fecha o caderno e o guarda sob a carteira. Levanta-se, vai até a frente da sala, próximo da professora.]

25. Professora: Que foi, Gil? [Pega sua mão e o conduz à carteira.] Pega o caderno.

26. Gil: [Senta-se novamente, pega seu caderno e o coloca sobre a carteira.]

27. Professora: Só vai ganhar depois que terminar, tá bom? [Referindo-se à folha com a atividade do dia.]

28. seu caderno, procurando a página correta. Abre em uma página.]

29. Professora: É esse o de hoje? [Aponta no caderno de Gil.]
30. Gil: [Fica olhando para o que está escrito no caderno.]

31. Professora: É, Gil? [Afasta-se da carteira de Gil e vai até a lousa.]

32. Gil: [Olha para a professora, olha para o caderno, olha para a lousa, vira a página.]

33. Professora: [Aproxima-se novamente e aponta para a página do caderno de Gil.] Ó! [Indica com o dedo algo escrito no caderno.] Tá igual?

34. Gil: [Aceno positivo com a cabeça.]

35. Professora: Tem o "l"? [Vai para a lousa e começa a apontar letra por letra da palavra "linguagem".]

36. Gil: [Aceno positivo com a cabeça, sem olhar para o caderno.]

37. Professora: Tem o "i"?

38. Gil: [Aceno positivo com a cabeça, sem olhar para o caderno.]

39. Professora: Olha no seu caderno!

40. Gil: [Olha para o caderno.]

41. Professora: Tem o "n"?

42. Gil: [Aceno positivo.]

43. Professora: Tem? E o "u"?

44. Gil: [Aceno positivo.]

45. Professora: Tem o "a"?

46. Gil: [Aceno positivo.]

47. Professora: Tem? [Aproxima-se de Gil e aponta em seu caderno o que Gil havia escrito.]

48. Gil: [Pega a borracha e apaga algo.]

49. Professora: Depois do "u"... 0 que é que tem lá depois do "u"? Olha lá. [Aponta para a lousa.]

50. Gil: [Olha para a lousa.]

51. Alguns alunos: "A"!

52. Gil: "A". [Volta a apagar e escreve "a".]

53. Professora: E depois do "a"? 0 que vem lá, Gil?

54. Gil: [Apaga novamente algo em seu caderno e escreve outra letra.]

55. Alunos: "G"

56. Professora: 0 Gil!

57. Professora: E depois do "g"?

58. Gil: [Apaga algo e escreve.] 
59. Professora: E depois do "g"?

60. Alunos: "E"!

61. Gil: [Apaga algo e completa a palavra "linguagem". Olha para a lousa.]

62. Professora: Já acabou, Gil. Não tem mais nada nesta linha. Você apagou aquilo que você fez a mais?

63. Gil: [Aceno positivo.]

64. Professora: Apagou todas?

65. Caio: [Aproxima-se e indica no caderno de Gil onde ele deve apagar.]

66. Professora: Mostra pra ele, tá bom?

67. Gil: [Apaga onde o aluno Caio indica.]

68. Caio: [Pega a borracha e apaga o que Gil havia feito a mais na página da direita.] 69. Pesquisadora: Gil, você não vai fazer o 5, ó? Você fez até o 4, faltam o 5 e o 6. [Apontando na lousa o que falta ser feito.] 70. Caio: [Pega o lápis e escreve o número 5 no caderno de Gil.]

71. Pesquisadora: Seu amigo marcou pra você, agora você copia o número 5 da lousa. 72. Gil: [Começa a escrever.]

73. Caio: [Continua a indicar a linha para Gil.]

74. Gil: [Olha na lousa e copia.]

75. Pesquisadora: Isso!

76. Caio: [Pega a borracha e apaga algo que Gil havia escrito errado. Aponta para Gil a linha de baixo.]

77. Gil: [Copia a última linha da rotina.]

78. Pesquisadora: Ele te ajudou?

79. Professora: [Aproxima-se de Gil, fecha o caderno para ele e lhe entrega a folha de atividade, mas neste instante toca o sinal para o recreio.]

Gil permanece na cópia do cabeçalho durante todo o primeiro período da aula e não realiza a atividade de linguagem. A professora revela sua preocupação em ajudá-lo a copiar o cabeçalho e a rotina (atividade que havia sido proposta para a classe toda). Durante o episódio, várias vezes a observamos realizar diferentes gestos e ações com o intuito de auxiliá-lo: aproxima-se da carteira de Gil, mostrando o que ele deve escrever; segura em sua mão e o ajuda a grafar a letra desejada; confere com Gil o que ele produziu; apaga ou o orienta a apagar o que escreveu a mais; indica as letras das palavras para o aluno. Os colegas também colaboram para que Gil conclua a tarefa e apropriam-se dos mesmos modos de atuação da professora: indicam, corrigem, apagam, soletram as letras, escrevem por ele. Gil realiza diferentes ações e gestos durante a atividade: olha para a lousa, escreve, apaga o que escreve, pede ajuda para a professora. Não se pode negar que há uma preocupação orientada para que Gil aprenda. Todos querem isso. Embora demore para fazer a cópia, ele a termina com o auxílio da professora e dos colegas.

Para refletir sobre essa situação, retomamos as proposições de Vigotski $(1987,2000)$ acerca da natureza social do desenvolvimento psicológico, quando argumenta que toda função psicológica superior foi antes uma relação social entre duas pessoas. A essa ideia está atrelado o conceito de internalização. Como explicou Pino (2000), Vigotski refere-se a três momentos significativos: o desenvolvimento em si, para os outros e para si. São várias as enunciações de Lourdes na tentativa de organizar as ações de Gil. Por meio de gestos e palavras, ela indica o que deve ser feito e chama a atenção do aluno ora para a lousa, ora para o caderno, com o intuito de que ele realize a cópia. Além disso, aproxima-se da carteira de Gil, toca nele, aprova aquilo que ele escreve corretamente e o questiona sobre o que deve ser reformulado.

Gil apropria-se de ações e gestos significativos realizados pela professora e pelos colegas, fazendo ele mesmo tais gestos e ações - apontar, olhar, apagar, escrever, nomear. Assim, em um primeiro momento, temos suas ações significadas pela professora e por seus pares; mas, à medida que essas ações se tornam significativas, convertem-se em ações para si. As interações sociais vividas nesse espaço escolar podem ser compreendidas como um trabalho de significação que implica incansáveis gestos indicativos - gestos de ensinar, conforme aponta Smolka (2010). 
Examinando o episódio, podemos afırmar que durante todo o tempo houve participação do outro para a realização da tarefa proposta; todavia, conforme aponta Góes (1997), as relações intersubjetivas nem sempre são harmoniosas e, na dinâmica dialógica, os envolvidos participam de diferentes formas. Quando a professora aproxima-se da lousa e aponta letra por letra da palavra linguagem, notamos movimentos de resistência, insistência e persistência de Gil, dos colegas e da própria professora, movimentos estes que culminam na escrita da palavra. $\mathrm{Na}$ análise da dinâmica interativa, consideramos que foram criadas possibilidades de caminhos diferenciados para a participação de Gil na atividade proposta.

Esse movimento conjunto da professora e dos colegas envolve Gil numa rede de significações própria das relações de ensino de nossas escolas. Entretanto, ao analisarmos o episódio a seguir, constatamos que a professora revela, na conversa com a pesquisadora, a dúvida sobre o efeito de suas ações e a incerteza sobre a aprendizagem de Gil. Vemos aí estampada sua angústia.

\section{Episódio 2}

Situação: Durante um dos encontros, a pesquisadora mostra para a professora um trecho de uma filmagem na qual ela contava a história de Chapeuzinho Vermelho para toda a classe. $\mathrm{Na}$ ocasião filmada, Gil mostra-se especialmente participativo e envolvido com a atividade. Após assistirem ao vídeo, elas conversam sobre o aluno e sobre os momentos em que ele participa ou não das atividades propostas.

1. Professora: Eu, assim, por exemplo, nessa [referindo-se à filmagem assistida] dá pra perceber que ele entende, ele fala, ele compreende o que está acontecendo. Só que tem momentos na sala em que eu falo com ele e ele não se manifesta, sabe? Às vezes, quando eu faço alguma pergunta, ele faz assim: "deixa eu ver" [coloca a mão no queixo, como se estivesse pensando], “deixa eu ver”... Se deixar, ele vai ficar 10,
20 minutos assim. Então, eu já experimentei falar "pessoal, vamos ouvir o que ele tem pra falar". Então agora é o momento dele, então eu fiquei, né? Talvez ele precise de mais um tempo pra expor a ideia dele, mas não, eu fiquei 5 minutos assim; ele: “deixa eu ver”... Aí ele começa a rir, aí ele abaixa a cabeça, então ele não fala. Eu tenho que fazer assim, por exemplo, se é uma votação pra um animal que eles querem saber sobre o animal, que eu trago um texto científico, aí eu falo "qual que você quer, Gil?" Aí ele fica "deixa eu ver" e nada... Dá risada, olha o colega, dá risada de novo... Aí eu falo assim: "Olha, a gente tem esses daqui”. Aí eu dou as opções pra ele: "cachorro, gato, borboleta, vagalume, qual que você quer?". Aí ele fica "hum, hum" [gesto de pensar], aí demora mais, aí eu falo, "é cachorro?". Aí ele fala "não”." "É gato?”. "Não”. Aí quando chega no que ele quer, ele faz assim (professora faz gesto afırmativo). Então eu não sei se ele tem vergonha de falar, se ele tem dificuldade para falar. É isso que eu queria entender. Por que ele não fala? Então eu tenho que dar as opções, eu tenho que ficar, sabe, tentando de alguma maneira descobrir a opinião dele, a ideia dele.

2. Pesquisadora: Então, eu entendo isso. Lógico que o que a gente quer é que a criança fale, que a criança participe...

3. Professora: Eu gostaria que ele falasse!

4. Pesquisadora: E aí eu acho que tem uma questão que eu já falei antes: ele é uma criança que precisa mesmo do outro.

5. Professora: Dessas opções.

6. Pesquisadora: Ele precisa de formas pra ajudar ele, parece que ainda ele sozinho, pra autonomia, ele não fala, "eu quero estudar a borboleta”. Mas se você vai dando as opções, ele chega lá, ele tem a opinião dele, mas ele precisa do outro.

7. Professora: Aí eu tenho dúvida, será que eu estou fazendo certo isso? Eu dando as opções, ou será que eu tenho que forçar ele a falar? Então, essa é a minha situação. 
8. Pesquisadora: Mas se a gente pensar, por exemplo, de coisas... Você é quem tem a história dele. Como você me falou do cabeçalho... Agora ele voltou [referindo-se à volta das férias], ele não está mais assim. Ele já está copiando. Então já houve situações em que você precisou muito dessa intervenção, de dar essas pistas, de mostrar, ensinar. Ele precisa de quem o ensine. $\mathrm{E}$ que agora ele já se vira...

9. Professora: Então é bom o que eu faço?

10. Pesquisadora: Eu acho que é esse o caminho.

\section{[...]}

11. Pesquisadora: Eu penso assim, o espaço da sala de aula é um espaço muito rico e muitas coisas vão ocorrendo ao mesmo tempo. Se a gente pensar nessa questão da inclusão, ele é mais um aluno que está lá, faz parte daquela sala de aula, não é um aluno que você vai trabalhar com ele isoladamente; e se a atividade é essa, de escolher os animais, então é isso. Qual é o jeito de fazer? Então, são esses caminhos que é preciso descobrir mesmo. Como ele vai fazer? Como ele vai descobrir? Essas atividades que envolvem a linguagem, a oralidade, são muito importantes! [...]

12. Professora: Agora, por exemplo, quando ele precisa de alguma coisa, ele fala assim: "Pessoal...". Ai todo mundo: "0 que, Gil? Fale, Gil". Aí ele tem que mostrar, tem que apontar. Ele já consegue chamar os colegas. É uma coisa que ele não fazia no ano passado. Ele não chamava o pessoal. Quando ele quer uma borracha, uma coisa, aí todo mundo vira pra ele: "0 que você quer?". Aí ele faz assim: o que ele quer, ele aponta, mostra.

13. Pesquisadora: Isso é importante, como ele usa, é a possibilidade de linguagem dele, e que isso seja significado. E aí pra gente poder pensar, o que é importante? A interação, essa relação dialógica, essa troca entre todos da sala de aula, professores e alunos, que ela possa acontecer e cada um vai participar disso com os recursos que tem. [...]
14. Pesquisadora: 0 que mudou nele, nessa questão da escrita? 0 que ele não sabia antes, que ele já sabe, desde quando você o conheceu?

15. Professora: Ele já tá... Quando eu o conheci ele usava letras aleatoriamente... Ele usava letras pra desenhar... Ele não sabia o que era aquilo... Ele repetia as atividades de leitura...

16. Pesquisadora: Ele até sabia nomear as letras?

17. Professora: É, mas ele não via função. Eu percebia isso, é uma coisa assim, o “a”, o "b"... Acho que foi uma coisa tão repetitiva pra ele no $1^{\circ}$ ano que ele conseguiu, isso ele apropriou. Aí o que eu tive dificuldade, ele ainda não usava o caderno, mesmo com aquela folha, com a linha mais grossa, então, era uma atividade diferente pra ele... É... Que mais? Eu senti que comigo ele conseguiu se expressar de outras formas, primeiramente, desenhava lindamente, atividade de música, nossa, se saía muito bem, eu sempre elogiando. Então, ele conseguiu superar até os outros em outras áreas. Então, desenho, ele adora desenhar, ele se sente mais tranquilo, os amigos dele falam: "Nossa, Gil, que lindo, deixa eu ver". Ele adora esse momento do desenho, ele adora o momento de música, ele tem uma noção de ritmo, que é... nossa... sabe, é mil! Aí eu percebi que nesses momentos e na relação comigo também, de fazer carinho, de ficar perto, de querer estar junto e eu com ele e isso aflora também comigo, aí a preocupação qual foi? E escrever, como nós vamos fazer? [...] Daí comigo agora ele consegue entender que as letras existem pra gente se expressar, ele sabe isso hoje, que o alfabeto é usado pra quê? Não é pra desenhar o alfabeto, porque ele desenhava o alfabeto antes. Pra que que existe $o$ alfabeto? Hoje ele tem essa noção. Ele usa o alfabeto pra escrever, pra colocar o que eu penso, falar do que eu quero escrever, uma frase, né? 
No início do episódio, nota-se que a professora revela acreditar na capacidade de seu aluno. Ela quer auxiliá-lo a encontrar um modo de se comunicar na sala de aula e, para isso, vale-se de algumas estratégias: dá tempo para ele pensar, dá opções para ele escolher o que quer dizer. Todavia, ela tem dúvidas em relação ao seu modo de atuação e questiona: "Será que eu estou fazendo certo isso?".

A pesquisadora ressalta a importância da participação do outro quando Gil ainda não consegue realizar a tarefa sozinho e faz indagações para a professora que podem ajudá-la a avaliar aquilo que já mudou em Gil, o que ele já aprendeu e o que ainda é difícil para ele. Ela também reflete sobre os caminhos alternativos de aprendizagem e indica que as ações realizadas pela professora podem ter ajudado na participação de Gil nas atividades e em suas conquistas.

0 questionamento da pesquisadora sobre o desenvolvimento de Gil - "o que mudou nele [...] o que ele não sabia antes, que ele já sabe [...]?"- auxiliou Lourdes a refletir sobre o processo de desenvolvimento de seu aluno e a constatar que há conceitos escolares que Gil já conhece - ou seja, que já estão consolidados e momentos em que ele ainda precisa do outro para elaborar seus conhecimentos. Diz ela: "ele usava letras aleatoriamente [...] pra desenhar [...] ele não via função [...] isso ele apropriou [...] hoje ele tem essa noção, ele usa o alfabeto pra escrever". Chamamos a atenção para a semelhança entre as ações da pesquisadora nesse episódio e as ações da professora no episódio anterior. A pesquisadora relaciona-se com a professora da mesma forma como esta se relaciona com Gil: apontando, questionando, chamando a atenção para o que é relevante.

Conforme já apontamos nas análises sobre o episódio 1, notamos que durante as relações entre Gil, a professora e seus colegas há momentos mais harmoniosos e situações mais conflitivas, que não permitem afırmar se houve ou não desenvolvimento em Gil. No episódio 2, pelos dizeres da professora Lourdes, constatamos que ela age buscando garantir a Gil o acesso ao conhecimento escolar. Retomamos aqui a noção de desenvolvimento proximal (VIGOTSKI, 1991a), que, vista de maneira prospectiva, supõe a participação do outro no processo de aprendizagem, em situações de elaboração partilhada. Atrelamos a essa ideia as considerações pertinentes de Góes (1997) sobre o papel contraditório do outro no processo de elaboração do conhecimento.

As ações da professora de Gil ganham um lugar importante se reconhecermos a relevância de sua participação no processo de elaboração do conhecimento escolar. É ela quem dá o tom, quem mostra para Gil, por meio de suas falas, ações e posturas, que é importante copiar o cabeçalho, reconhecer as letras, escrever.

A professora escolheu um caminho para seguir: ficar perto, apontar, olhar, nomear, mostrar, escrever, esperar por Gil. Outros caminhos e/ou recursos poderiam ser utilizados, melhores ou piores, mais fáceis ou mais difíceis. 0 importante é garantir a qualidade de vivência do aluno com necessidades educacionais especiais, considerando sempre que, acima do caminho que se escolha ou do recurso especial que se utilize, a linguagem, os signos e os sentidos estão partilhados e elaborados nos diversos contextos.

\section{Considerações finais}

Pensamos que ainda é preciso refletir mais profundamente sobre o que se espera dos educadores e alunos em relação a essa ação colaborativa. 0 que vem a ser agir colaborativamente? A ideia de ação colaborativa atrelada ao conceito de significação nos remete à procura da compreensão sobre as relações que se estabelecem em sala de aula, que permitem a elaboração de novos sentidos pelo grupo de alunos e pelo professor.

É possivel afırmar que há uma ação colaborativa ocorrendo na sala de aula e que há interesse e preocupação da professora nesse sentido. Mas como essas ações se atrelam ao processo de significação? Quais são as possibilidades de elaboração de novos sentidos? 0 
estudo aqui apresentado mostrou que as possibilidades de ação residem nos processos interativos e nas significações produzidas na dinâmica escolar. Envolvem uma inter-relação de professores e alunos que buscam a constituição dos múltiplos sentidos partilhados no contexto escolar.

Problematizarapossibilidadedeelaboração de novos sentidos, a nosso ver, torna-se central para a compreensão dos caminhos alternativos de aprendizagem e dos recursos especiais referidos por Vigotski (1997) em suas proposições sobre as possibilidades de aprendizagem de pessoas com deficiência. Para o autor, a superação das dificuldades encontra-se nas relações sociais e nas mediações proporcionadas pelo outro, por signos e instrumentos, ou seja, pela mediação social-semiótica.
Ressaltamos aqui que a professora, ao refletir junto com a pesquisadora sobre suas próprias ações, consegue compreender sua participação no processo de significação e desenvolvimento de seu aluno. Assim, destacamos o importante papel que o outro tem no processo de ensino e aprendizagem. Vigotski afırma que as leis gerais de desenvolvimento são iguais para todas as crianças, ou seja, a criança aprende na relação social com o outro. No caso das crianças com deficiência, isso não será diferente. Explicitar modos de ação que permitam criar formas culturais singulares pode contribuir, no âmbito educacional, para tornar o processo de ensino significativo também para os alunos com necessidades educacionais especiais.

\section{Referências}

BEYER, Hugo Otto. A educação inclusiva: incompletudes escolares e perspectivas de ação. Revista Cadernos de Educação Especial, Santa Maria, n. 22, p. 1-9, 2003. Disponível em: <http://coralx.ufsm.br/revce/ceesp/2003/02/r3.htm>. Acesso em: 22 mar. 2012.

BRASIL. Congresso Nacional. Lei n 9.394, de 20 de dezembro de 1996. Estabelece as diretrizes e bases da educação nacional. Diário Oficial da União, Brasília, n. 248, seção 1, p. 27.833, 23 dez. 1996. Disponível em: <http://www.planalto.gov.br/ccivil_03/ Leis/L9394.htm>. Acesso em: 21 mai. 2012.

COLAÇO, Veriana de Fátima Rodrigues et al. Estratégias de mediação em situação de interação entre crianças em sala de aula. Estudos de Psicologia, Natal, v. 12, n. 1, p. 47-56, abr. 2007. Disponível em: <http://www.scielo.br/pdf/epsic/v12n1/a06v12n1>. Acesso em: 26 mar. 2012.

FERREIRA, Marília Mendes. Constraints to peer scaffolding. Trabalhos em Linguística Aplicada, Campinas, v. 47, n. 1, p. 9-29, jun. 2008. Disponível em: <http://www.scielo.br/pdf/tla/v47n1/v47n1a01.pdf>. Acesso em: 16 abr. 2012.

FREITAS, Ana Paula de. Zona de desenvolvimento proximal: a problematização do conceito através de um estudo de caso. Tese (Doutorado em Educação) - Faculdade de Educação, Universidade Estadual de Campinas, Campinas, 2001.

GÓES, Maria Cecília R. As relações intersubjetivas na construção de conhecimentos. In: GÓES, Maria Cecília R.; SMOLKA, Ana Luiza B. (Orgs.). A significação nos espaços educacionais: interação social e subjetivação. Campinas: Papirus, 1997. p. 11-28.

. A abordagem microgenética na matriz histórico-cultural: uma perspectiva para o estudo da constituição da subjetividade. Cadernos Cedes, Campinas, v. 20, n. 50, p. 9-25, abr. 2000. Disponível em: <http://www.scielo.br/pdf/ccedes/v20n50/a02v2050. pdf>. Acesso em: 23 abr. 2012.

MURDOCH, B. E. Desenvolvimento da fala e distúrbios da linguagem: uma abordagem neuroanatômica e neurofisiológica. Rio de Janeiro: Revinter, 1997. 
PINO, Angel. 0 social e 0 cultural na obra de Vigotski. Educação e Sociedade, Campinas, v. 21, n. 71, p. 45-78, jul. 2000. Disponível em: <http://www.scielo.br/pdf/es/v21n71/a03v2171.pdf>. Acesso em: 13 mar. 2013.

SMOLKA, Ana Luiza B. 0 (im)próprio e o (im)pertinente na apropriação das práticas sociais. Cadernos Cedes, Campinas, v. 20, n. 50, p. 26-40, abr. 2000. Disponível em: <http://www.scielo.br/pdf/ccedes/v20n50/a03v2050.pdf>. Acesso em: 23 abr. 2012.

Ensinar e significar: as relações de ensino em questão ou das (não) coincidências nas relações de ensino. In: SMOLKA, Ana Luiza B.; NOGUEIRA, Ana Lúcia H. (Orgs.). Questões de desenvolvimento humano: práticas e sentidos. Campinas: Mercado das Letras, 2010. p. 107-128.

VIGOTSKI, Lev S. Historia del desarrollo de las funciones psíquicas superiores. Ciudad de La Habana: Científico-Técnica, 1987.

A formação social da mente. São Paulo: Martins Fontes, 1991a.

Obras escogidas. Madrid: Centro de Publicaciones del M.E.C., 1991b. t. I.

Obras escogidas. Madrid: Visor, 1997. t. V.

Psicologia concreta do homem. Educação e Sociedade, Campinas, v. 21, n. 71, p. 23-44, jul. 2000. Disponível em:

<http://www.scielo.br/pdf/es/v21n71/a02v2171.pdf>. Acesso em: 13 mar. 2013

Recebido em: 11.06.2012

Aprovado em: 14.11.2012

Maria Inês Bacellar Monteiro é doutora em Psicologia e docente do Programa de Pós-Graduação em Educação da Universidade Metodista de Piracicaba.

Ana Paula de Freitas é doutora em Educação e docente do Programa de Pós-Graduação em Educação do Centro Universitário Moura Lacerda. 